\title{
The Agulhas Leakage: the missing link in the interhemispheric climate seesaw?
}

Gianluca Marino ${ }^{1}$ and Rainer Zahnn 2,3

\begin{abstract}
The Agulhas Leakage is a key component of the Atlantic Meridional Overturning Circulation. Unraveling the past patterns of leakage variability and associated heat and salt anomalies into the Atlantic Ocean holds clues for their role in ocean and climate changes.
\end{abstract}

The Atlantic Meridional Overturning Circulation (AMOC) modulates climate on a range of temporal and spatial scales. The northward heat transport associated with its upper limb ameliorates the North Atlantic climate, while its southward flowing lower limb transfers carbon from the atmosphere into the ocean interior (Visbeck 2007; Lozier 2012). Processes taking place in the Northern Hemisphere are historically regarded as the main drivers of the AMOC through their direct influence on the North Atlantic Deep Water (NADW) formation (Lozier 2012). Mounting evidence, however, emphasizes that the inter-ocean exchange of water south of Africa (Beal et al. 2011) and the upwelling of deep water offshore Antarctica (Visbeck 2007) are also potentially important control factors for the AMOC. We are focusing here on the transport of warm and saline waters from the subtropical Indian Ocean by the Agulhas Current, which flows southward along the shelf edge of southern Africa. While most of the Agulhas Current water recirculates into the Indian Ocean, a variable fraction, Agulhas Leakage (AL), escapes into the South Atlantic Ocean (Beal et al. 2011). Recent studies contend that the $A L$ sets the southern control for the Atlantic upper ocean buoyancy budget and thus ultimately for the AMOC variability. Potential mechanisms for buoyancy control include planetary-wave adjustments in the Atlantic thermocline and/or advection of salt to the NADW formation sites (Beal et al. 2011 and references therein).

\section{Paleo-reconstructions of \\ the Agulhas Leakage}

Several approaches have been used to investigate past $\mathrm{AL}$ dynamics. In their seminal study, Peeters et al. (2004) tracked the inter-ocean transport of Indian Ocean subtropical waters into the South Atlantic, using variations in tropical-subtropical planktic foraminifera, the Agulhas Leakage Fauna. From reconstructions of sea surface temperature (SST) and productivity changes Bard and Rickaby (2009) inferred the position of the Subtropical Front. Its meridional migrations reflect the oceanographic response to changes in the westerlies, impacting the width of the Indian-to-Atlantic oceanic gateway and, in turn, the inter-ocean water exchange (Beal et al. 2011). SST and seawater stable oxygen isotope $\left(\delta^{18} \mathrm{O}_{\mathrm{sw}^{\prime}}\right.$ a qualitative proxy for salinity) fluctuations, based on paired $\mathrm{Mg} / \mathrm{Ca}-\delta^{18} \mathrm{O}$ data in planktic foraminifera, allowed changes in inter-ocean heat and salt transports to be deciphered (Marino et al. 2013). All these reconstructions consistently show that the AL intensified during glacial terminations. However,

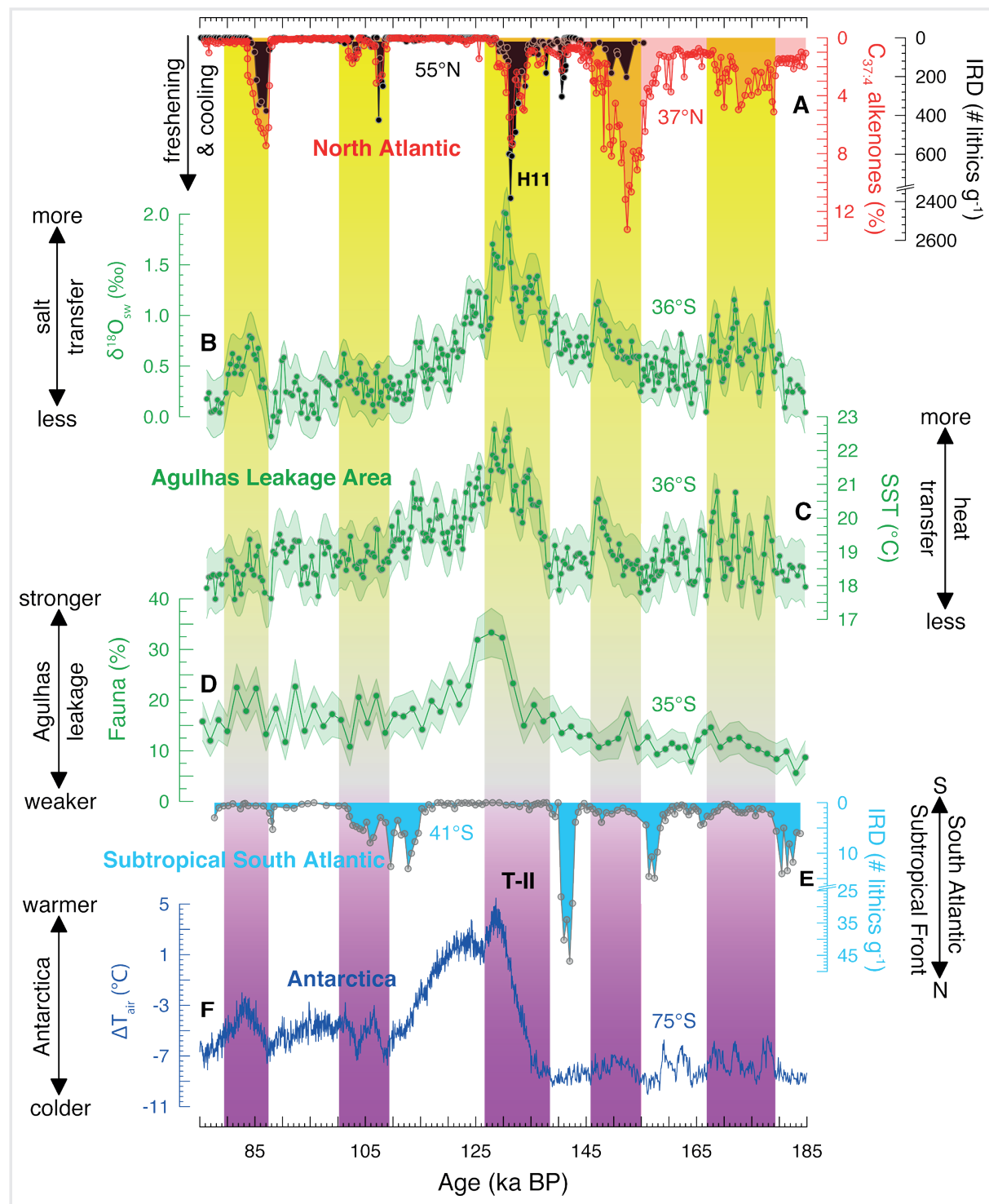

Figure 1: Agulhas leakage variability and interhemispheric climate change across the penultimate glacialinterglacial cycle. (A) North Atlantic Ice Rafted Debris (IRD, black) from ODP site 980 (Oppo et al. 2006) and tetraunsaturated alkenones ( $C_{37 \cdot 4}$ red) from MD01-2444 (Martrat et al. 2007). (B, C) Seawater stable oxygen isotopes $\left(\delta^{18} \mathrm{O}_{\mathrm{SW}}\right)$ and sea surface temperatures (SST) from MD96-2080 (Marino et al. 2013). (D) Agulhas Leakage Fauna from GeoB3603-2 (Peeters et al. 2004). Uncertainty envelopes (2 $\sigma$ ) are shown in B-D. (E) IRD from MD022588 (Marino et al. 2013). (F) Antarctic temperature anomaly from EPICA Dome C ice core (Jouzel et al. 2007). Vertical bands highlight intervals of North Atlantic cooling and Agulhas leakage strengthening. T-II=glacial Termination II; H11=Heinrich event 11. Figure modified from Marino et al. (2013). 

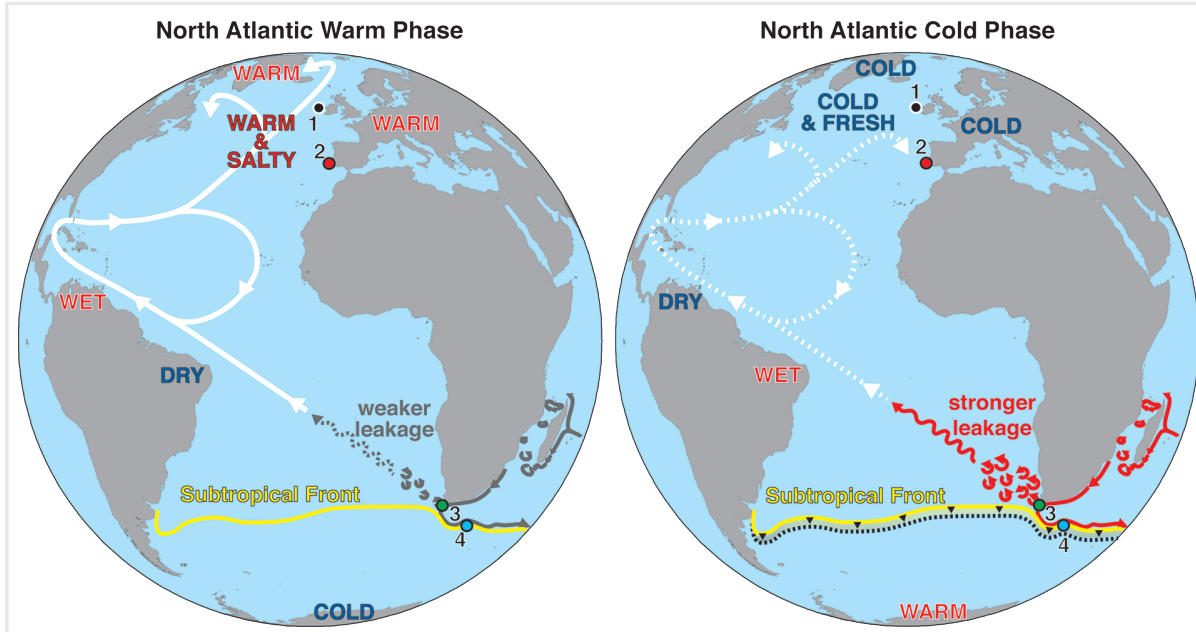

Figure 2: Sketch illustrating the relationship between Agulhas Leakage (AL) and North Atlantic climate. North Atlantic warm phase; the Atlantic Meridional Overturning Circulation (AMOC) is strong, while the AL is weak. North Atlantic cold phase; the AMOC weakens, likely due to enhanced freshwater discharge into the North Atlantic. The attendant changes in the interhemispheric ocean and atmospheric circulation cause the southward shift and potential intensification of the mid-latitude westerlies in the Southern Hemisphere, accompanied by the southward migration of the Subtropical Front that strengthens the AL. Core locations are shown: ODP 980 (1), MD01-2444 (2), MD96-2080, GeoB3603-2 (3) and MD02-2588 (4).

comparison of high- (Marino et al. 2013) and low-resolution (Peeters et al, 2004) records spanning the penultimate glacial-interglacial cycle reveal that maxima in salinity, SST, and (where sufficiently resolved) faunal assemblages associated with the $A L$, as well as southward shifts of the regional oceanic fronts, were not limited to the prominent change across glacial Termination II (T-II). Rather smaller-scale maxima also coincided with several millennial-scale episodes of North Atlantic cooling and freshening and concurrent Antarctic warming during glacial and interglacial times (Fig. 1A-F).

\section{Millennial-scale Agulhas \\ Leakage variability}

The paleo-evidence discussed above testifies to the link between variations in $A L$ strength and interhemispheric or even global climate changes. In particular the Pleistocene glacial terminations feature prominent $A L$ events. The detailed paleoceanographic reconstructions spanning T-II (Fig. 1) document that: (1) the AL maximum of T-II coincided with Heinrich event 11 (Marino et al. 2013), when the North Atlantic was cold and the AMOC weak (Fig. 1A-D); (2) as was the case during earlier glacial terminations (Peeters et al. 2004), the AL maximum was limited to the termination and did not extend into the subsequent interglacial, which featured only transient and low-amplitude AL intensifications (Marino et al. 2013) (Fig 1B-D); (3) more anticyclonic eddies carrying warm and saline waters entered the South Atlantic (Scussolini et al. 2013).

Based on these observations and previous paleoceanographic analysis, we propose that the AL and its influence on the South Atlantic hydrography in the past were dominated by variability on a millennial timescale. The "terminal leakage events" during glacial-interglacial transitions were millennial-scale maxima of inter-ocean transport that, like their smaller scale counterparts, developed in response to AMOC weakening and ensuing North Atlantic cooling (Fig. 2). This initiated a sequence of feedback responses that impacted the Southern Hemisphere westerlies (Lee et al. 2011), with knock-on consequences for the position of the regional oceanic fronts and AL strength. During glacial terminations, large $\mathrm{CO}_{2}$ rise (Toggweiler et al. 2006) and sustained Southern Ocean warming (Knorr and Lohmann 2007) may explain the particularly strong AL indicated by the data, e.g. by amplifying the responses of the Southern Hemisphere westerlies and the Subtropical Front. Nevertheless, questions remain on the postulated interplay between changing wind field and the AL strength. In fact, the scenarios inferred from the paleorecords seem to disagree with state-of-the-art numerical simulations, which, however, are only run with modern boundary conditions (Durgadoo et al. 2013).

\section{Outlook}

Despite the strong paleoceanographic evidence for an AL involvement in glacial-interglacial transitions and possibly in more abrupt climate episodes (Peeters et al. 2004; Marino et al. 2013), it remains to be determined whether the $A L$ responded passively to these changes or played an active role in them. Analysis of the temporal phasing suggests that $A L$ maxima lead $A M O C$ strengthening. Based on that, one can argue that the AL was both a passive and an active player. The leakage intensified passively in response to AMOC weakening/North Atlantic cooling (passive role), but the attendant negative buoyancy forcing may then have actively contributed or even caused the subsequent AMOC resumption (Knorr and Lohmann 2007; Beal et al. 2011).

Several limitations prevent us from unambiguously solving this riddle. The detailed phasing between AL fluctuations and changing $A M O C$ is limited by difficulties inherent in aligning the paleo-records from the southern tip of Africa with those from the North Atlantic and Antarctica (Marino et al. 2013). Paleo-modeling supports the hypothesis that intensified leakage and $\mathrm{AMOC}$ resumption are coupled (Knorr and Lohmann 2007). Explaining the apparent temporal offset between AL strengthening and AMOC resumption would require a buoyancy threshold for reinvigorating NADW formation. However, quantitatively constraining the buoyancy threshold is limited by our ability to quantitatively translate paleo- $\delta{ }^{18} \mathrm{O}_{\mathrm{sw}}$ variations into salinity changes, because the $\delta^{18} \mathrm{O}_{\text {sw }}$-salinity relationship varied in the past particularly in regions dominated by advective processes (Rohling and Bigg 1998).

To identify the exact role of the $\mathrm{AL}$ in climate change, the focus of paleoceanographic research must shift to a quantitative analysis of the heat and salt transports around the southern tip of Africa and across the Atlantic Ocean. The high-amplitude leakage events at glacial terminations may be used to reconstruct with a higher degree of confidence the signal propagation into and across the Atlantic Ocean, thereby serving as templates for the millennial-scale leakage maxima that punctuated glacial and interglacial climates.

\section{ACKNOWLEDGEMENTS}

This research was funded by European Commission Seventh Framework Programme, projects "Past4Future" (grant no. 243908) and "Gateways" (grant no. 238512). G. Marino also thanks the Universitat Autonoma de Barcelona (postdoctoral research grant no. PS-68801/08) and the Spanish Ministry of Science and Innovation (PROCARSO project, grant no. CGL2009-10806).

\section{DATA}

Data presented here are available from the corresponding author and are in the process of being submitted to NOAA NCDC.

\section{AFFILIATIONS}

'Research School of Earth Sciences, The Australian National University, Canberra, Australia

${ }^{2}$ Institució Catalana de Recerca i Estudis Avançats (ICREA), Barcelona, Spain

Innstitut de Ciència i Tecnologia Ambientals (ICTA) and Departament de Física, Universitat Autònoma de Barcelona, Cerdanyola del Vallès, Spain

\section{CONTACT}

Gianluca Marino: gianluca.marino@anu.edu.au

\section{REFERENCES}

Bard E, Rickaby REM (2009) Nature 460: 380-393

Beal LM et al. (2011) Nature 472: 429-436

Durgadoo JV et al. (2013) J Phys Oceanogr 43: 2113-2131

Jouzel J et al. (2007) Science 317: 793-796

Knorr G, Lohmann G (2007) Geochem Geophys Geosyst 8, doi:10.1029/2007GC001604

Lee S-Y et al. (2011) Paleoceanography 26 doi:10.1029/2010PA002004

Lozier MS (2012) Annu Rev Mar Sci 4: 291-315 Marino G et al. (2013) Paleoceanography 28: 599-606 Martrat B et al. (2007) Science 317: 502-507 Oppo DW et al. (2006) Quat Sci Rev 25: 3268-3277 Peeters FJC et al. (2004) Nature 430: 661-665 Rohling EJ, Bigg GR (1998) J Geophys Res Oceans 103 : 1307-1318

Scussolini P et al. (2013) Clim Past 9: 2631-2639

Toggweiler JR et al. (2006) Paleoceanography 21, doi:10.1029/2005PA001154

Visbeck M (2007) Nature 447: 383 